\title{
A construção social de gênero na Biologia: preconceitos e obstáculos na biologia molecular*
}

\author{
Neide Mayumi Osada** \\ Maria Conceição da Costa***
}

\begin{abstract}
Resumo
Este paper tem como objetivo analisar a presença de homens e mulheres nas ciências biológicas a partir do Projeto Genoma Fapesp (PGF). Baseado nos estudos sociais das ciências e nos estudos de gênero em ciências, pretende-se, portanto, entender as principais razões que levam ao avanço mais lento na carreira das mulheres pesquisadoras, analisar como ocorre a participação das mulheres na construção das ciências e, por fim, avaliar os principais obstáculos por elas enfrentados.
\end{abstract}

Palavras-chave: Gênero, Mulheres e Ciência, Biologia Molecular, Projeto Genoma.

\footnotetext{
* Recebido para publicação em agosto de 2006, aceito em setembro de 2006.

*** Mestre em Política Científica e Tecnológica do Instituto de Geociências da Unicamp.neidemo@usp.br

${ }^{* * * * *}$ Professora do Instituto de Geociências e pesquisadora do Núcleo de Estudos de Gênero - Pagu, ambos da Unicamp. dacosta@ige.unicamp.br
} 
A construção social de gênero na Biologia

Social Construction of Gender in Biology:

Prejudice and Barriers in Molecular Biology

\begin{abstract}
This paper analyses the presence of women and men in Biological Sciences, specifically at the Fapesp Genome Project. Considering the Social Studies of Sciences and Gender Studies, this article highlights the barrier and prejudices women face in their scientific carrier and show how this reproduces a situation in which men advance faster than women.
\end{abstract}

Key Words: Gender, Women and Science, Molecular Biology, Genome Project 
Neide Osada e Conceição Costa

\section{Introdução}

Os estudos sociais da ciência têm apontado, com distintas abordagens, o fazer ciência como construção social. A proposta de construção, ainda criticada por áreas de conhecimento fora das ciências sociais - que inaugura essa preocupação - surge da idéia de desconstruir valores iluministas das ciências (neutralidade, objetividade, universalidade, metodologia) e, em seu lugar, pensar em uma ciência polifônica, polivalente, inclusiva e eqüitativa do ponto de vista de gênero. (Haraway, 2001) Os valores que ainda prevalecem sobre as ciências são masculinos e, em alguns casos, hostis à participação feminina.

Para Haraway, as teorias feministas e a construção social das ciências defendem a destruição da idéia de que a ciência é um espaço de grandes verdades a serem aplicadas, e propõem, em seu lugar, a idéia de ciência como constructo social. Sua proposta é a introdução do que ela chama de conhecimentos situados: "objetividade feminista significa simplesmente conhecimentos situados" (Id.:173), em oposição à idéia de conhecimentos universais. Dessa forma, faz sentido falar em produção do conhecimento a partir das experiências, histórias de vida $e$ backgrounds dos cientistas. Somado à isso, a idéia que se persegue é a da construção de uma ciência "livre de gênero" (Haraway, 2000), no entanto, para que isso seja possível é preciso pensar na inclusão da perspectiva feminista à ciência.

Para entender a adoção da perspectiva feminista é preciso situar algumas correntes dos estudos de gênero em ciência. De acordo com Gonzáles (2005), entre as diversas abordagens, encontram-se: a) epistemologia feminista pós-estruturalista, da qual Donna Haraway pertence; b) feminismo perspectivista (feminist standpoint), corrente liderada por Sandra Harding, Nancy Harstock, Hillary Rose, entre outras, que defende a construção de uma ciência baseada no ponto de vista feminino, $e$ neste caso, a ciência assume a perspectiva feminista e se torna ciência feminista; c) feminismo contextual, liderado por Helen 
A construção social de gênero na Biologia

Longino, Elizabeth Anderson e Lynn Nelson, que propõe uma ciência construída por ambos os sexos. Esta última visão não defende a formação de uma ciência feminista, mas a inclusão da perspectiva feminista no processo de produção das ciências. ${ }^{1}$

Longino (2001), em Can there be a feminist science?, não concorda com os objetivos do feminismo perspectivista. Para a autora, as mulheres não produzem uma outra ciência $e$, como afirmou Schienbinger (2001), as mulheres não se conectam na bancada do laboratório e fazem outra ciência. O que ela defende é a inclusão da perspectiva da mulher à ciência, esta sim diferenciada. Para ela, o mais importante é focalizar as ciências "mais como prática do que como conteúdo, mais como processo que produto; portanto, não se trata de uma ciência feminista, mas "fazer ciência sobre a perspectiva feminista". (Longino, 2001:217)

Sob o mesmo ponto de vista, Keller (2004) também concorda com a inclusão desse "olhar diferenciado" que as mulheres detêm sobre a ciência, sobre o material de pesquisa $e$ suas relações com o mundo da pesquisa. No livro A Feeling for the Organism, no qual Keller analisa a biografia de Barbara McClintock, a autora não descreve apenas a vida dessa importante bióloga molecular, laureada com o Prêmio Nobel em 1982, mas percebe as diferentes relações que McClintock mantém com sua pesquisa e seu objeto.

Entretanto, a inclusão da perspectiva feminista não significa afirmar que a objetividade na investigação das ciências deva ser abandonada. Keller e Longino alertam para o fato de que "objetividade científica precisa ser reconcebida como a função de uma estrutura comunal, e nunca como propriedade individual de cientistas". (Keller, 2004:217)

Um ótimo exemplo da discussão gênero versus ciência são as transformações no campo da Biologia desde o início do século

\footnotetext{
1 Além das três correntes citadas, há outras abordagens dentro dos estudos de gênero em ciência, mas que não tratadas nesse artigo. Entre outros, ver Lopes, 1998; Citeli, 2000; González, 2005; Sardenberg, 2002.
} 
$\mathrm{XX}$ e nas relações de gênero no processo de consolidação das técnicas e estudos da biologia molecular.

Para analisar a participação das mulheres na biologia, levamos em conta os processos de mudanças, ruptura $e$ crescimento das ciências que, em certos casos, levam à invisibilidade, esquecimento ou isolamento da mulher. A primeira parte do texto propõe uma reflexão sobre a saída das mulheres na botânica inglesa e suas razões. A segunda parte trata do surgimento da biologia molecular e do lançamento do PGF. Os dados do projeto indicam que as cientistas mulheres foram "esquecidas" no processo de desenvolvimento e lançamento do projeto, apesar de coordenarem $29 \%$ dos laboratórios. Essa nova ruptura tem conseqüências na produção científica da mulher? Homens e mulheres constroem diferentemente suas carreiras científicas?

\section{A profissionalização da ciência: a botânica como campo masculino?}

A presença de mulheres na produção científica da biologia desde o período anterior à sua profissionalização (século XIX) é marcada por rupturas, presenças e ausências. A construção da botânica "moderna" expulsa as mulheres desse campo, "desfeminiza" a ciência e tem "dificuldades" de reconhecer as contribuições das mulheres. (cf. Shteir, 1997)

Até a primeira metade do século XIX, como aponta Henson, a botânica era considerada um

objetivo apropriado para as mulheres interessadas na natureza desde os anos 1760. (...) A botânica tornou-se um passatempo popular na era vitoriana, com muitas mulheres colecionando e prensando amostras de samambaias e flores silvestres. (Henson, 2000:174)

Essa área do conhecimento tornou-se identificada com as mulheres, que tomavam notas, preparavam ilustrações científicas $e$ trabalhavam na editoração e publicação de resultados de 
pesquisas de campo, campo este que lhes foi vetada a participação.

Conforme Shteir (1997), John Lindley, presidente da Sociedade Lineana de Londres e professor de botânica da recémcriada Universidade de Londres, em sua aula inaugural em 1830, afirma que a botânica deveria assumir uma abordagem mais científica (menos descritiva e mais focada nos estudos fisiológicos da planta) e, para tanto, a saída das mulheres era imprescindível para o crescimento da ciência.

Não se pretende fazer um estudo histórico, em profundidade, da biologia, no entanto, para compreender a presença (e a ausência) da mulher nas ciências e construção de suas carreiras científicas, resgatamos alguns marcos históricos da construção da biologia no país e da história da biologia européia.

A profissionalização da ciência, que ocorre na Europa, principalmente na segunda metade do século XIX, transforma radicalmente a ciência. Esse processo leva à criação de universidades modernas (a exemplo da Universidade de Londres, que surge justamente para contrapor às universidades de Oxford $e$ Cambridge, consideradas velhas para os objetivos da profissionalização da ciência), à instalação de laboratórios de pesquisa para trabalho coletivo e à criação de institutos de pesquisa, museus e outras instituições de apoio à ciência. Nesse contexto, aparece a figura do cientista profissional, aquele que irá se dedicar à pesquisa em tempo integral e pelo qual será remunerado. (Landes, 1994) Esses fatores levarão ao fim da atividade de pesquisa como hobby ou da pesquisa individual, como corria nos laboratórios privados.

Para Auger (1962), a importância do século XIX para a ciência pode ser observada pelo aumento do número de pesquisadores e de publicações científicas. Em 1800, havia cerca de 100 publicações científicas; cinqüenta anos mais tarde o número passou para 1.000 , no início do século $\mathrm{XX}$ foram registradas 10.000 publicações e no começo do século XXI as estimativas são de mais de um milhão. Ciência passa a ser 
pensada como desenvolvimento social, econômico e militar, como produção coletiva - não mais individual - e na inversão de grandes somas de recursos, como foi o caso da Big Science e dos projetos genomas. $\mathrm{Na}$ Inglaterra, a experiência da profissionalização da botânica viabilizou a criação de instituições de pesquisas modernas, tornou a biologia uma área do conhecimento mais palatável aos jovens de classe média ${ }^{2}$, que passaram a encontrar nas universidades espaço para a formação profissional adequada a seu perfil. Por outro lado, essa experiência foi cruel para as botânicas. Essas mulheres que se dedicaram à ciência - ilustraram importantes livros de botânica, de introdução e de divulgação científicas - não tiveram suas competências reconhecidas e foram "expulsas" da produção científica. (Shteir, 1997)

A única forma de participação dessa nova ciência era através de uma educação formal em universidades, no entanto, as mulheres eram proibidas de freqüentá-las. Em 1829, John Lindley, de modo inequívoco, declara que

a ciência da botânica deveria abordar a estrutura da plantas ao invés da identificação e classificação. Botânica deveria caminhar fora das idéias de Lineu - que o rotulou de "estragado", "estático" e "superficial" - e deveria, no lugar, analisar a partir da perspectiva Continental. (Shteir, 1997:31)

$\mathrm{Na}$ Inglaterra, a partir da segunda metade do século XIX, pressões do movimento feminista e do movimento popular levaram à abertura das universidades às mulheres inglesas. No Brasil, a importância dos estudos da botânica, desde a sua emergência, institucionalização e profissionalização se dá, principalmente, pela biodiversidade nacional e pela relevância do setor agrícola. Aqui, a permissão para entrada das mulheres no ensino superior ocorre em 1879, mas devido a separação por sexo

2 Até a primeira metade do século XVIII, a botânica era considerada uma ciência feminina. 
A construção social de gênero na Biologia

no ensino secundário a maioria das alunas não poderia prestar os exames de admissão às faculdades. Berta Lutz, uma das cientistas brasileiras mais importantes, liderando o movimento sufragista, consegue a abertura do Colégio D.Pedro, escola normal oficial para moças em 1922. Esse advento permitiu que as jovens pudessem prestar os exames do ensino superior, uma vez que as escolas normais para moças não as preparavam para os exames de latim, gramática e filosofia. (Marcílio, 2005)

Biologia Molecular: a genômica é um campo masculino?

A Biologia Molecular, ciência que promoveu o desenvolvimento de projetos genomas, desenvolve-se ao longo do século XX e apresenta três marcos relevantes: o descobrimento da estrutura de DNA (1953), das técnicas de RNA recombinante (1970) e de novas técnicas e equipamentos (1995) que automatizaram o processo de seqüenciamento do genoma de organismos vivos.

Em 1953, James D. Watson, Francis Crick, Maurice Wilkins e Rosalind Franklin descobriram a estrutura do DNA. Essa descoberta só foi possível por intermédio dos estudos de Franklin que, através da cristalografia, obteve as imagens do DNA, levando a representação - a dupla hélice - de sua estrutura. Considerada uma das cientistas mais importantes da biologia molecular cuja vida e trabalho foram rodeados de inúmeras situações preconceituosas, controvérsias, Franklin talvez tenha sido uma das maiores injustiçadas da história da biologia. Os três pesquisadores, Crick, Watson e Wilkins receberam o Prêmio Nobel em 1962 pela descoberta, quatro anos após a morte de Franklin, causada pela superexposição ao Raio X.

A partir da descoberta da estrutura do DNA, Kevles e Geison (1995:97) relatam o fortalecimento da Biologia Molecular ao longo do século XX: "a Biologia experimental está se transformando numa das áreas mais poderosas, modernizando a concepção da natureza e da vida". Esse fortalecimento, em parte, é justificado pelas descobertas científicas, cujas principais são a técnica do DNA 
recombinante ${ }^{3}$ e a reação em cadeia da polimerase $(\mathrm{PCR}) .{ }^{4} \mathrm{Os}$ autores mostram que o desenvolvimento de qualquer área do conhecimento não é natural, mas acontece porque há interesses por parte de grupos de cientistas, da política científica ou da sociedade.

A descoberta da estrutura do DNA, o desenvolvimento de novas técnicas de análise e a introdução de equipamentos mais precisos e sofisticados tornaram possível o lançamento do projeto genoma humano americano e seu fechamento em tempo recorde. O mapeamento do genoma humano levou quatro anos para ser concluído: 3\% no final de 1997; 7,1\% em novembro de 1998; $22 \%$ em setembro de 1999; 47\% em dezembro de 1999 e 100\% em fevereiro de 2001.

Em São Paulo, o Projeto Genoma da Fundação de Amparo à Pesquisa do Estado de São Paulo (Fapesp), menos pretensioso e mais focalizado, foi lançado em 1997, sete anos após o PGH americano e teve como princípio norteador as melhorias sociais $e$ econômicas. Fernando Perez, então diretor científico da Fapesp, afirmou em entrevista que a criação do projeto visava ampliar a produção científica na área da biologia molecular e, além disso, teria como meta beneficiar a sociedade a partir de seus resultados. (Hamburger, 2004) Como o projeto genoma humano americano, o seqüenciamento do genoma da Xylella também ocorreu em tempo recorde, não pelo desenvolvimento de máquinas mais

3 DNA produzido a partir da divisão de fragmentos de DNA de dois ou mais organismos distintos. Fonte: Divin into de Gene Pool. http://www.exploratorium. edu/genepool/

${ }^{4}$ PCR é acrónimo de Polymerase Chain Reaction, reação em cadeia da polimerase, "É um método de amplificação (de criação de múltiplas cópias) de DNA (ácido desoxirribonucleico) sem o uso de um organismo vivo". In: Wikipedia, enciclopédia Livre. http://pt.wikipedia.org/wiki/Polymerase_Chain_ Reaction 
eficientes, mas pela dedicação de sete pesquisadoras, ganhadoras do Prêmio Claudia de Ciência. ${ }^{5}$

As instituições de fomento à pesquisa no país têm papel crucial na consolidação das ciências modernas. A aprovação de um projeto temático ${ }^{6}$ na Fapesp ou qualquer outra instituição de financiamento garante ao pesquisador e à sua equipe recursos financeiros para aquisição de equipamentos, reforma da infraestrutura, garantia dos suprimentos para pesquisa (laboratórios, informática, etc.), reserva técnica, custeio de participação em eventos no país e no exterior, entre outras facilidades. Ela também certifica o grupo de pesquisa quanto à sua competência na área, torna o pesquisador visível na comunidade científica e, quando os resultados alcançam a mídia, torna-se referência na área junto à sociedade.

Dessa forma, é fundamental saber quais são as áreas prioritárias das ciências para conhecer quem faz ciência no país. Os dados, abaixo (tabela 1) mostram o número de Projetos Temáticos aprovados na Fapesp de 1992 a 2004. ${ }^{7}$ Ao longo da década de 1990, é possível acompanhar historicamente as áreas de maior prestígio, ou de acordo com a Fapesp, "área de relevância da pesquisa para o desenvolvimento da Ciência $e$ Tecnologia".

Os projetos temáticos aprovados nas áreas da biologia, ciência da computação e química ${ }^{8}$ de 1992 até 2004 mostram que, na somatória geral de 232 projetos financiados, $31 \%$ foram

5 O Prêmio Cláudia de Ciências é uma iniciativa da Editora Abril que, desde 1996, premia mulheres que se destacam em varias e distintas áreas de atuação profissional. Ver: http://claudia.abril.com.br/premioclaudia/index.shtml

${ }^{6}$ De acordo com a Fapesp, "a modalidade Projeto Temático financia grandes pesquisas, em geral de quatro anos, envolvendo equipes maiores de pesquisadores, em geral de vários departamentos ou instituições, visando à obtenção de resultados científicos ou tecnológicos e socioeconômicos de maior impacto".(www.fapesp.br)

7 Os dados para 2004 são resultados parciais.

8 Principais áreas do conhecimento que compõe os estudos da genômica. 
concedidos às mulheres. A ciência da computação obteve financiamento em seis projetos, todos coordenados por homens. A química obteve 44 projetos temáticos aprovados, a maioria no período de 1996-1997 e 2000-2001, desse total $14 \%$ foram concedidos à mulheres.

As ciências biológicas tiveram, nesse período, 182 projetos temáticos aprovados, desse total $36 \%$ foram coordenados por mulheres. A biologia é considerada eqüitativa do ponto de vista do gênero ${ }^{9}$, e se avaliado pela participação de alunos e alunas na graduação e na pós-graduação, a carreira poderia ser considerada feminina. Como entender, então, a lentidão com que as mulheres avançam nas ciências?

Tabela 1

Distribuição de recursos Fapesp concedidos, não aprovados e em análise por área do conhecimento, ano e sexo - 1998 a 2005 - Projeto Temático

\begin{tabular}{|c|c|c|c|c|c|c|c|c|c|c|c|c|c|c|c|c|c|c|c|c|c|c|c|c|}
\hline \multirow{3}{*}{ REA } & \multicolumn{15}{|c|}{ Concedido } & \multirow{2}{*}{\multicolumn{3}{|c|}{\begin{tabular}{|c|}
$\begin{array}{c}\text { Concediclo } \\
\text { Total }\end{array}$ \\
$1992-2005$ \\
\end{tabular}}} & \multirow{2}{*}{\multicolumn{3}{|c|}{\begin{tabular}{|c|}
$\begin{array}{c}\text { cancelado } \\
\text { Total }\end{array}$ \\
$1992-2005$ \\
\end{tabular}}} & \multirow{2}{*}{\multicolumn{3}{|c|}{\begin{tabular}{|c} 
Total Globa \\
$1992-2004$ \\
\end{tabular}}} \\
\hline & \multicolumn{3}{|c|}{\begin{tabular}{|c|}
$1992-1994$ \\
\end{tabular}} & \multicolumn{3}{|c|}{\begin{tabular}{|l|l|} 
1995-1997 \\
\end{tabular}} & \multicolumn{3}{|c|}{ 1998-2000 } & \multicolumn{3}{|c|}{\begin{tabular}{|c|}
$2001-2003$ \\
\end{tabular}} & \multicolumn{3}{|c|}{\begin{tabular}{|l|}
$2004-2005$ \\
\end{tabular}} & & & & & & & & & \\
\hline & $\mathbf{T}$ & $\mathbf{F}$ & $\%$ & $T$ & $\mathbf{F}$ & $\%$ & $T$ & $\mathbf{F}$ & $\%$ & $\mathbf{T}$ & $F$ & $\%$ & $T$ & $\mathbf{F}$ & $\%$ & $T$ & $\mathbf{F}$ & $\%$ & $\mathbf{T}$ & $\mathbf{F}$ & $\%$ & $T$ & $F$ & \\
\hline RON & 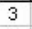 & & 33 & 8 & & 0 & 10 & 1 & 10 & 8 & 7 & 25 & & & & 30 & 4 & 13 & 35 & 10 & 29 & 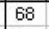 & 14 & \\
\hline 10 & 1 & & 0 & & & & 1 & 1 & 0 & 1 & & 0 & 1 & & & & 2 & 50 & 6 & 2 & 33 & 0 & 4 & \\
\hline & & & 0 & 19 & 6 & 2 & 16 & & - & 17 & 8 & 47 & 3 & 2 & t & 59 & 20 & 34 & o & 5 & 56 & & 25 & \\
\hline BOTANAIC & & & 100 & & 3 & 0 & & & & 1 & & & & & & & & 54 & 1 & & 50 & & 4 & \\
\hline & & & 0 & 2 & & & 10 & 2 & & 4 & 1 & & & & & & 4 & 21 & 1 & 7 & & & 2 & \\
\hline & & & & & & & & & & & & ) & & & & & 1 & 33 & 10 & 2 & 20 & 14 & 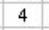 & \\
\hline FARM & & & 0 & 6 & 2 & & 5 & 1 & & s & 5 & 5 & & & & & 8 & 35 & & 1 & 11 & & U & \\
\hline & & & & 4 & & & & & & & 3 & & 5 & 1 & 2 & 1 & 7 & 23 & & 2 & 33 & & 9 & \\
\hline GENE & & 1 & 0 & 2 & & & 9 & E & 67 & 7 & 2 & 29 & & 4 & 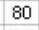 & 24 & 14 & 58 & 23 & 10 & 43 & 47 & 24 & \\
\hline & & & 0 & 5 & 2 & 40 & 11 & 5 & 45 & & & & & 1 & 20 & 6 & 12 & 46 & & 3 & 33 & 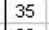 & 5 & \\
\hline & & & & & & & & & & 2 & 1 & & & & & & & 14 & & & 73 & & 9 & \\
\hline & & & 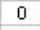 & 2 & & 0 & & & 0 & 1 & 1 & 100 & & & & & 1 & 20 & 5 & 1 & 20 & 1 & 2 & \\
\hline & & & 100 & & & & 3 & & 33 & 3 & , & 33 & & & & & & 38 & & 2 & 67 & 11 & 5 & \\
\hline & 9 & 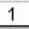 & 11 & 12 & 1 & 8.3 & 18 & 3 & 11 & 13 & 4 & 3 & 11 & 2 & 18 & 03 & 11 & 17 & 24 & 7 & 29 & 91 & 19 & \\
\hline tal Global & 29 & 7 & 24 & 63 & 17 & 27 & 99 & 27 & 27 & 82 & 33 & 40 & 42 & 11 & 26 & 315 & 95 & 30 & 178 & 67 & 38 & 511 & 166 & \\
\hline
\end{tabular}

Fonte: Fapesp, 2006. Elaboração das autoras

9 Para Maffia (2002:29), a ciências humanas no Brasil é a única área do conhecimento feminina, as ciências biológicas e da saúde são carreiras eqüitativas. 
A categoria Auxílio à Pesquisa Regular da Fapesp ${ }^{10}$ concedeu 2642 recursos financeiros, de 1992 a 2004 a pesquisadores individuais com vínculo em instituições de pesquisa no Estado de São Paulo, desse total $49 \%$ foram concedidos a pesquisadoras e $51 \%$ a homens nas áreas das ciências biológicas. Nesse tipo de financiamento, as mulheres obtiveram recursos financeiros na mesma proporção que homens.

O programa especial Jovem Pesquisador, da mesma instituição, tem como objetivo principal oferecer condições adequadas de trabalho para pesquisadores sem vínculo empregatício em instituições de pesquisa e que, de acordo com a Fapesp, tenham "expressiva produção científica ou tecnológica". O programa prevê a formação de um grupo de pesquisa com orçamento para bolsas (de iniciação científica ao pós-doutorado), aquisição de equipamentos, suprimentos para pesquisa, auxílio viagem entre outras categorias. A instituição deve obedecer o critério de centro emergente e o tempo de duração do projeto é de até quatro anos. A participação por gênero na obtenção desse tipo de inversão é bastante desigual, de 1992 até 2004, apenas 40\% das pesquisadoras nas áreas das ciências biológicas foram beneficiadas (tabela 2).

De acordo com dados do CNPq, as áreas do conhecimento que mais cresceram nas ciências biológicas, entre 2001 e 2005, são genética, microbiologia e bioquímica. Entretanto, é preciso assinalar que o número de bolsas concedido dobrou em praticamente todas as áreas do conhecimento nesse período. Vale destacar os indicadores de bolsas concedidas no exterior e de fomento à pesquisa, pois elas apontam para áreas de interesse ou da identificação de "janelas de oportunidades", como são os casos

${ }^{10} \mathrm{O}$ Auxilio à Pesquisa Regular Fapesp tem como objetivo financiar pesquisas individuais por até dois anos. 
da genética e da bioquímica, principais áreas que formam as bases teóricas para a biologia molecular. ${ }^{11}$

Tabela 2

Programas de Apoio à pesquisa na biologia por sexo (1992-2004)

\begin{tabular}{l|c|c|c|}
\multirow{2}{*}{ Programas de Pesquisa Fapesp } & \multicolumn{3}{|c}{$1992-\mathbf{2 0 0 4}$} \\
\cline { 2 - 4 } & $\mathbf{T}$ & $\mathbf{F}$ & $\%$ \\
\hline Projetos Temáticos & 182 & 66 & 36 \\
\hline Jovem Pesquisador & 164 & 66 & 40 \\
\hline Genoma & 218 & 88 & 40 \\
\hline Total & 564 & 220 & 39 \\
\hline
\end{tabular}

Fonte: Fapesp, 2004

$\mathrm{T}=$ Total; $\mathrm{F}=$ Pesquisadores do Sexo Feminino; \%= porcentagem de mulheres sobre o total.

Elaboração das autoras

De acordo com a tabela 1, participação por sexo nos projetos temáticos por subárea, as áreas que menos receberam recursos foram: biologia geral, biofísica, microbiologia $e$ morfologia. Se comparadas com a tabela 2, investimentos do CNPq, é possível perceber que a biofísica recebeu, em 2001, 1.346 recursos de fomento à pesquisa, zero em 2002, 131 em 2003 e 60 em 2004, enquanto que a Fapesp, em 1999, aprovou apenas três projetos temáticos, de um total de seis, ao longo dos 12 anos analisados. As áreas que tiveram mais projetos temáticos aprovados foram: bioquímica (31\% coordenados por mulheres), fisiologia (22\%), farmacologia (32\%), imunologia $(52 \%)$ e genética (56\%).

\footnotetext{
${ }^{11}$ De acordo com os dados do $\mathrm{CNPq}$, a área de microbiologia apresenta aumento subido no fomento à pesquisa de 117 para o que pode indicar erro de digitação já que não se observou tamanho crescimento em outras áreas.
} 
A construção social de gênero na Biologia

Tabela 3

CNPq - Investimentos realizados em bolsas e no fomento à pesquisa segundo área do conhecimento - 2001-2004 - São Paulo (1)

\begin{tabular}{|c|c|c|c|c|c|c|c|c|c|c|c|c|c|c|c|c|}
\hline \multirow{2}{*}{$\begin{array}{l}\text { Área do } \\
\text { conhecimento }\end{array}$} & \multicolumn{4}{|c|}{ Bolsa no País } & \multicolumn{4}{|c|}{ Bolsa no Exterior } & \multicolumn{4}{|c|}{ Fomento à Pesquisa } & \multicolumn{4}{|c|}{ Total } \\
\hline & 2001 & 2002 & \begin{tabular}{|l|}
2003 \\
\end{tabular} & 2004 & 2001 & 2002 & 2003 & 2004 & 2001 & 2002 & 2003 & 2004 & \begin{tabular}{|l|}
2001 \\
\end{tabular} & \begin{tabular}{|l|l|}
2002 \\
\end{tabular} & \begin{tabular}{|l|l|}
2003 \\
\end{tabular} & 2004 \\
\hline Biofisica & 595 & 632 & 708 & 898 & 84 & 112 & 60 & 65 & 1,346 & 0 & 131 & 60 & 2,024 & 744 & 900 & 1,024 \\
\hline Biologia Geral & 242 & 259 & 307 & 265 & 0 & 0 & 0 & 0 & 1,029 & 30 & 110 & 245 & 1,272 & 289 & 417 & 510 \\
\hline Bioquímica & 2,231 & 2,643 & 3,251 & 4,281 & 260 & 307 & 245 & 375 & 518 & 532 & 1,144 & 864 & 3,009 & 3,483 & 4,639 & 5,520 \\
\hline Botânica & 1,304 & 1,266 & 1,761 & 2,316 & 5 & 32 & 4 & 12 & 192 & 193 & 135 & 191 & 1,501 & 1.492 & 1.900 & 2,519 \\
\hline $\begin{array}{l}\text { Ciência da } \\
\text { Computaçẫo }\end{array}$ & 2,660 & 2,546 & 3.110 & 3.458 & 273 & 241 & 88 & 257 & 2,058 & 2,105 & 1,671 & 843 & 4,991 & 4,892 & 4,869 & 4,558 \\
\hline Ecologia & 1.703 & 1.888 & 2,053 & 2.415 & 87 & 130 & 84 & 41 & 311 & 143 & 258 & 409 & 2.101 & 2,161 & 2,395 & 2,865 \\
\hline Fisiologia & 1,321 & 1.330 & 1.878 & 2,660 & 69 & 114 & 123 & 147 & 555 & 544 & 800 & 229 & 1.946 & 1,989 & 2,801 & 3,036 \\
\hline Genética & 2,235 & 2,596 & 3,377 & 4,385 & 8 & 55 & 78 & 175 & 678 & 796 & 943 & 1.130 & 2,221 & 3.447 & 4,399 & 5,690 \\
\hline Imunologia & 845 & 995 & 1,252 & 1,832 & 31 & 69 & 70 & 90 & 341 & 175 & 1,538 & 356 & 1.217 & 1,239 & 2,860 & 2,278 \\
\hline Mcrobiologia & 789 & 837 & 1,171 & 1,745 & 333 & 274 & 132 & 126 & 117 & 272 & 313 & 2,018 & 1,239 & 1,383 & 1,616 & 3,889 \\
\hline Mbrrologia & 985 & 899 & 948 & 1.171 & 0 & 50 & 69 & 74 & 41 & 81 & 97 & 86 & 1.026 & 1,029 & 1.113 & 1.331 \\
\hline Parasitologia & 514 & 542 & 728 & 1.125 & 0 & 0 & 0 & 0 & 304 & 156 & 189 & 135 & 817 & 698 & 917 & 1,260 \\
\hline Química & 5,950 & 6.299 & 7.712 & 9.957 & 143 & 281 & 102 & 259 & 978 & 803 & 833 & 2,846 & 7.071 & 7,382 & 8,647 & 13,062 \\
\hline Total & 21,375 & 22,732 & 28.256 & 36,509 & \begin{tabular}{|l|}
1,292 \\
\end{tabular} & 1.666 & 1,056 & 1,621 & 8.468 & 5,829 & 8.161 & 9,413 & 31,135 & 30,228 & 37.473 & 47,542 \\
\hline
\end{tabular}

Fonte: Cnpq, 2005 (VELLOSO, 2001)

A análise dos projetos temáticos em biologia por subárea do conhecimento mostra que a participação da mulher varia de acordo com a temática. Os dados mais interessantes são para genética na qual as mulheres coordenaram $56 \%$ dos temáticos (tabela 1), ou seja, 10 projetos de um total 18 . Na avaliação histórica da área de genética, entre 1992 e 1997, foram aprovados apenas dois projetos temáticos, ambos coordenados por mulheres. O Gráfico 1 apresenta a participação por sexo do corpo docente nos cursos de biologia das principais universidades do Estado, no geral, as mulheres representam $47 \%$ do total. 
Neide Osada e Conceição Costa

Gráfico 1

Distribuição de docentes do curso de biologia da Unesp, Unicamp e USP $-2005$

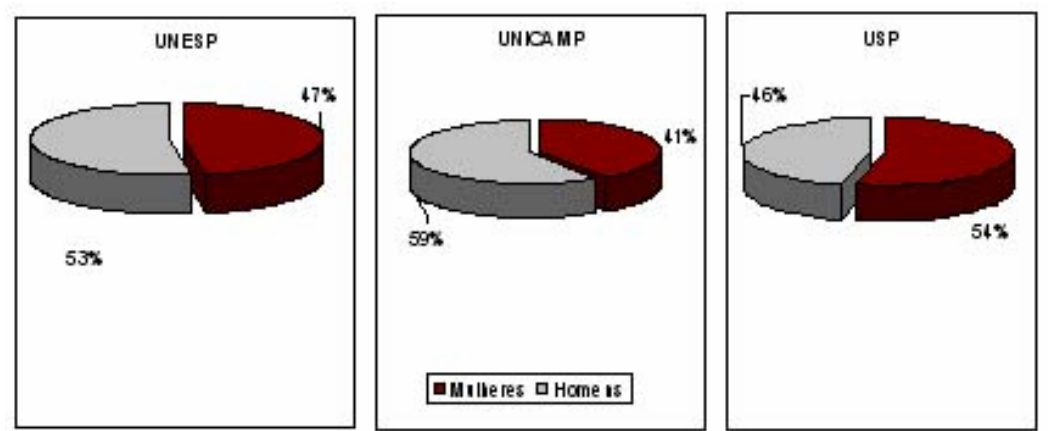

Fonte: USP, Unesp e Unicamp, 2005. Elaboração das autoras.

A análise por departamento mostra que a botânica é uma área feminina tanto na USP (13 de um total de 22 vagas), quanto na Unesp (10 de 13); na Unicamp as mulheres ocupam 50\% das vagas (9 de 18). No departamento de Genética e Evolução da USP, as mulheres ocupam $61 \%$ das vagas $(21$ mulheres de um total de 34 vagas); no entanto, na Unesp e na Unicamp, a participação é majoritariamente masculina, sendo $66 \%$ e $70 \%$ respectivamente (gráfico 2). A Unicamp e a Unesp possuem algumas características em comum como grande número de departamentos totalizando uma média de 12 , enquanto a USP possui apenas cinco departamentos. 
A construção social de gênero na Biologia

Gráfico 2

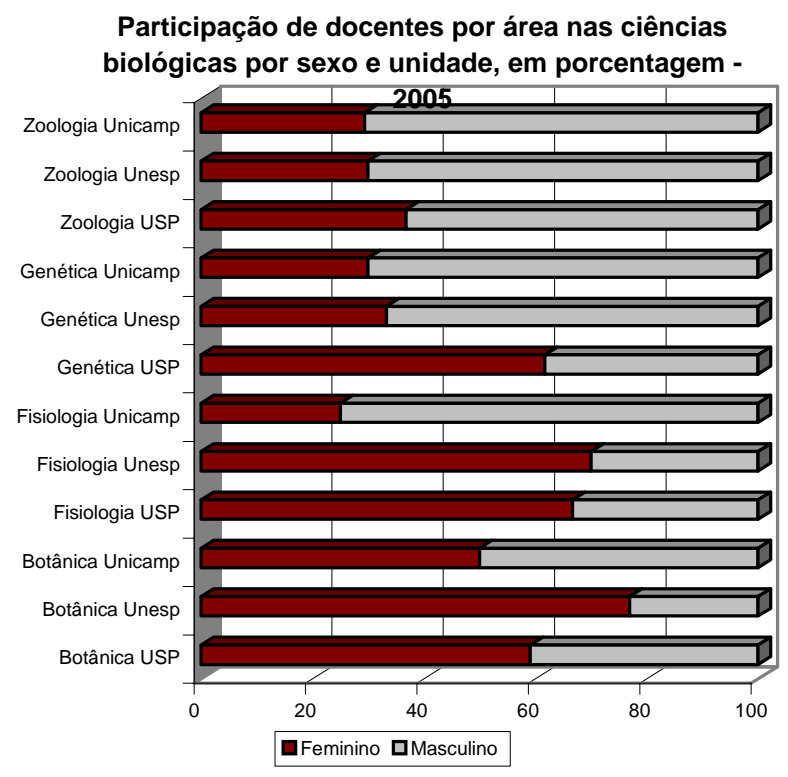

Fonte: Unesp, Unicamp e USP, 2005 [Elaboração própria]

Os dados quantitativos do projeto genoma da Xylella indicam que a maioria das mulheres participou do projeto na bancada do laboratório, enquanto pesquisadoras de iniciação científica, mestrandas ou doutorandas, cuidando de atividades de rotina do laboratório. O núcleo de coordenadores e consultores que organizou e desenhou o projeto genoma em 1997 foi composto aproximadamente por 18 pesquisadores (Hamburger, 2004), sendo a maioria especialista em biologia molecular e bioquímica, outros pesquisadores das áreas da agronomia, da saúde e da ciência da computação também foram convidados. Os consultores internacionais - pesquisadores da Inglaterra, Bélgica e França - tiveram participações importantes nos projetos genomas 
de seus países. Interessante observar que o thinktank do genoma foi composto por um grupo de 18 pesquisadores ligados às ciências da vida e nenhuma mulher pesquisadora formou parte do grupo.

O primeiro projeto, Xylella, não pode ser definido simplesmente como um projeto acadêmico de pesquisa como conhecemos; este projeto foi a escola na qual pesquisadores aprenderam, cooperativamente, a mapear geneticamente organismos vivos, a analisar o material produzido $e$ a transformar conhecimento em soluções para problemas que atacam a agricultura. O projeto trouxe uma série de benefícios não só para a pesquisa nacional, permitindo que a infra-estrutura dos laboratórios fosse modernizada e (super) equipada e possibilitando que seus pesquisadores ganhassem competência numa das áreas que mais cresce no mundo da pesquisa $e$ oferecendo visibilidade internacional aos pesquisadores e à pesquisa nacional.

A escolha dos coordenadores dos laboratórios de seqüenciamento se deu pela análise curricular; a maioria dos pesquisadores demonstrava experiência na área de biologia molecular e em estudos em genômica no exterior. Dentre os 34 laboratórios que integram a rede, $71 \%$ são coordenados por homens e $29 \%$ por mulheres. Dos 171 pesquisadores que participaram no projeto Xylella, $52 \%$ são mulheres e $48 \%$ homens (ver gráfico 3).

A partir da segunda metade do século $\mathrm{XX}$, as mulheres ampliaram sua participação nas ciências biológicas como estudantes de graduação e pós-graduação, docentes $e$ pesquisadoras, no entanto, os homens continuaram assumindo as posições mais importantes na hierarquia das ciências. Assim se deu no Projeto Genoma Fapesp onde as principais decisões e articulações foram tomadas por um grupo formado por 18 pesquisadores, todos homens; nos projetos coletivos da mesma instituição os homens dirigem $61,34 \%$ de toda pesquisa produzida e os cargos de decisão de instituições ligadas às ciências são, em sua maioria, ocupados por homens. 
Gráfico 3

Projeto Genoma Xylella: participação por sexo, em porcentagem - 1997

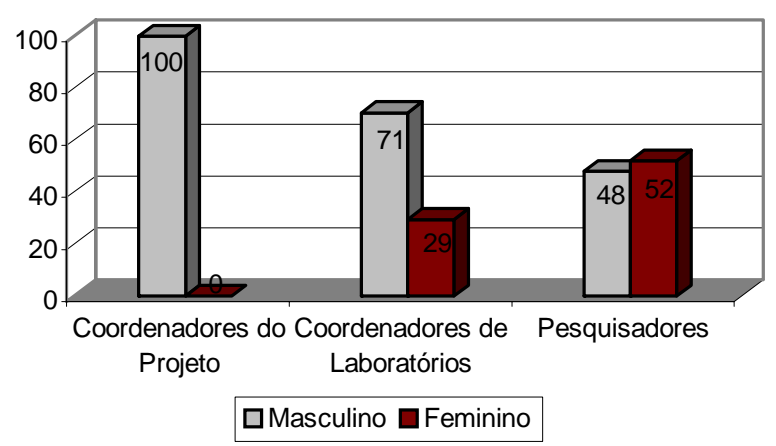

Fontes: Fapesp, 2005 , "Fapesp 40 anos abrindo fronteiras" e Fapesp, 2004. Elaboração das autoras

Os dados da Fapesp indicam que as mulheres avançaram muito nas ciências biológicas da graduação ao pós-doc, representando $60 \%$ dos alunos. Na universidade, elas são $47 \%$ do total de docentes (gráfico 1) e apenas $17 \%$ dos professores titulares (Academia Brasileira de Ciências, 2003). Elas são avaliadas de forma inadequadas já que as instituições de pesquisa e de fomento parecem defender o "feminismo da igualdade", ou seja, homens e mulheres são iguais e são avaliados igualmente. Ao não perceber as diferenças entre os sexos, a ciência impõe que a mulher se adapte ao perfil masculino.

\section{Considerações finais}

Tentamos demonstrar que as mulheres ganham espaços nas ciências como resultado de esforço pessoal, apesar de as instituições de fomento à pesquisa, docência e pesquisa serem lideradas na maioria por homens e que acabam criando ambientes poucos adequados às mulheres. 
O mapeamento sobre a pesquisa financiada pela Fapesp indica que nas subáreas do conhecimento da biologia de maior concentração de mulheres, e de maior prestígio, avaliado de acordo com a porcentagem de projetos temáticos aprovados (tabela 1), as mulheres coordenam, proporcionalmente, menos projetos coletivos. São exemplos as áreas da fisiologia, cuja participação aproximada de mulheres na área é de $60 \%$, e imunologia e bioquímica, áreas de participação mais igualitária das mulheres. A botânica, que recebeu menos recursos, teve $83 \%$ dos projetos coordenados por mulheres.

Não é possível afirmar que existe discriminação contra as mulheres perante as instituições financiadoras de pesquisa. As ciências biológicas constituem-se ainda um dos "redutos da razão impessoal" (Perez Sendeño, 1992); as ideologias iluministas das ciências - universalidade, objetividade e racionalidade continuam presentes entre as instituições ligadas às ciências, $e$ pesquisadores, homens e mulheres, entrevistados para essa pesquisa. A perniciosidade encontra-se no fato que tais ideologias são valores masculinos, o que implica dizer que a ciência produzida sob o olhar feminino será sempre criticada $e$ questionada.

Nesse sentido, a contribuição das mulheres ao projeto genoma não foi percebida $e$ o fato de sete mulheres conquistarem o Prêmio Cláudia de Ciência em 2000, pelo êxito no fechamento do genoma da Xylella, "foi apenas uma coincidência", nas palavras de uma das entrevistadas. Isso aponta também para a rejeição à incorporação da perspectiva feminista na produção do conhecimento científico. Neste caso, perdem as ciências.

\section{Referências bibliográficas}

AUGER, Pierre. Current Trends in Scientific Research: survey of the main trends of inquiry in the field of natural sciences the dissemination of scientific knowledge for peaceful ends. Paris, Unesco, 1962. 
A construção social de gênero na Biologia

CITELI, M. T. Mulheres nas ciências: mapeando campos de estudo. Cadernos Pagu (15), Núcleo de Estudos de Gênero - Pagu/Unicamp, 2000.

GONZÁLEZ, V.S. Una Introducción a los estúdios sobre ciência y gênero. Argumento de Razón Técnica, no 8, 2005.

HAMBURGER, Amélia Império. Fapesp 40 anos: abrindo fronteiras. São Paulo, Fapesp/Edusp, 2004.

HARAWAY, Donna. Situated Knowledge: the science question in feminism and the privilege of partial perspective. In: LEDERMAN, Muriel e BARTSCH, Ingrid. The gender and science reader. London/New York, Routledge, 2001.

A manifest for cyborgs: science, technology, and socialist feminist in the 1980. In: KIRKUP, G. et alii. The gendered cyborg: a reader. New York, The Open University/Routledge, 2000.

HENSON, Pamela. A invasão da Arcádia: As cientistas no Campo na América Latina, 1900-1950. Cadernos Pagu (15), Núcleo de Estudos de Gênero - Pagu/Unicamp, 2000.

KELLER, Evelyn Fox. What implact, if any, has feminism had on science? J. Biosci, vol. 29, n¹, março de 2004, pp.7-13.

LANDES, D. Prometeu Desacorrentado: transformação tecnológica $e$ desenvolvimento industrial na Europa ocidental, desde 1750 até a nossa época. Rio de Janeiro, Nova Fronteira, 1994.

LONGINO, H. Can there be a feminist science? In: WYER, Mary et alii. (org.) Women, Science and Technology. Nova York, Routledge, 2001.

LOPES, M.M. "Aventureiras" nas ciências: refletindo sobre gênero e história das ciências naturais no Brasil. Cadernos Pagu (10), Núcleo de Estudos de Gênero - Pagu/Unicamp, 1998.

LOPES, M.M e COSTA, M.C., Por que tão devagar nas ciências e nos estudos de gênero em ciências, 2004, mimeo.

LOPES, M.M e COSTA, M.C., Problematizando ausências: mulheres, gênero e indicadores na História das ciências. In: MORAES, M.L. Q. [org.], Gênero na Fronteira do Sul, Campinas, Coleção Encontros, Pagu/ Núcleo de Estudos de Gênero, Unicamp, 2005. 
MAFFIA, D. Crítica feminista à Ciência. In: COSTA, Ana Alice A. e SARDENBERG, Cecília M.B. (org.) Feminismo, Ciência e Tecnologia, Redor e Núcleo de Estudos Interdisciplinas sobre a Mulher $\mathrm{FFCH} /$ UFA, 2002.

MARCÍLIO, Maria Luiza. História da escola em São Paulo e no Brasil. São Paulo, Instituto Braudel/Imprensa Oficial do Estado, 2005.

SARDENBERG, C. M. B. Da crítica feminista da ciência à ciência a uma ciência feminista. In: Feminismo, Ciência e Tecnologia, Coleção Bahiana, Salvador, Redor, 2002.

SCHIENBINGER, L. O Feminismo Mudou a ciência? São Carlos, Edusc, 2001.

PÉREZ SEDEÑO, Eulália. La enseñanza de la historia de las ciencias y los estudios sobre la mujer. Revista da Sociedade Brasileira de História das Ciências, n 7, janeiro/junho de 1992, pp.25-30.

SHTEIR, Ann B. Gender and "Modern" Botany in Victorian England. Osiris (12), 1997, pp.29-38.

VELLOSO, J. (org.) A pós-graduação no Brasil: formação e trabalho de mestres e doutores no país. Brasília, mimeo, 2001. 